\title{
Desarrollo del pensamiento crítico reflexivo a través de la enseñanza de la historia en Benguela
}

\author{
Development of reflexive critical thinking through the teaching of history \\ in Benguela
}

\section{Desenvolvimento do pensamiento crítico reflexivo a través do ensino da história em Benguela}

\author{
Âurea Augusto Luís Wafunga ${ }^{1}$, Antonio-Manuel Rodríguez-García ${ }^{2}$, Arturo Fuentes Cabrera ${ }^{3}$ \\ ${ }^{1}$ Universidad de Katyavala Buíla, Angola (aritaluis@hotmail.com) \\ ${ }^{2}$ Universidad de Granada, España (arodrigu@ugr.es) \\ ${ }^{3}$ Universidad de Granada, España (arturofuentes@ugr.es)
}

Recibido el 4 de mayo de 2017; revisado el 9 de mayo de 2017; aceptado el 5 de agosto de 2017; publicado el 1 de junio de 2018

\section{RESUMEN:}

El pensamiento crítico y reflexivo es una característica necesaria para los docentes en el contexto actual. A partir de la observación y la experiencia como docentes en el Instituto Superior de Ciencias de la Educación de Benguela de la Universidad de Katyavala Buíla vemos que la ilustración de la historia en la Licenciatura de Enseñanza de la Historia contribuye poco al desarrollo del pensamiento crítico y reflexivo. Esto es un aspecto muy relevante si tenemos en cuenta la necesidad de formar a buenos docentes críticos y reflexivos que sean capaces de promover un pensamiento crítico en sus estudiantes de manera que cuestionen los diferentes contextos sociales. El estudio que aquí presentamos consistió en analizar el pensamiento crítico-reflexivo a través de la enseñanza de la historia. Para ello se utilizó la observación no participante y un cuestionario. La información recogida mostró que los encuestados señalan una baja contribución de la enseñanza de la historia al desarrollo del pensamiento crítico y reflexivo. De este modo, se necesitan adapotar nuevas estrategias metodológicas con el fin de promover habilidades tales como: el análisis, la crítica, la reflexión, el razonamiento y la comprensión de los problemas en un entorno histórico.

\section{PALABRAS CLAVE: PENSAMIENTO CRÍTICO} Y REFLEXIVO, ENSEÑANZA DE LA HISTORIA, FORMACIÓN DEL PROFESORADO.

\begin{abstract}
:
Critical and reflective thinking is a necessary characteristic of the teacher in the present context. Based on observation and experience as teachers at the Institute of Education Sciences of Benguela, University of Katyavala Buíla, we see that the teaching of history in the Degree in Teaching History contributes little to the development of critical and reflective thinking. This is a very relevant aspect if we consider the need to train good critical and reflective teachers who are able to promote critical thinking in their students in a way that questions the different social contexts. The study presented here consisted in analyzing criticalreflexive thinking through the teaching of history. Non-participant observation and a questionnaire
\end{abstract}


were used for this purpose. The information gathered showed that the respondents point to a low contribution of the teaching of history to the development of critical and reflective thinking. In this way, new methodological strategies need to be adapted in order to promote skills such as: analysis, criticism, reflection, reasoning and understanding of problems in a historical setting.

KEYWORDS: CRITICAL AND REFLECTIVE THINKING, TEACHING HISTORY, TEACHER TRAINING.

\section{RESUMO:}

O pensamento crítico e reflexivo constitui uma característica necessária ao professor no contexto actual. A partir da observação e da experiência enquanto professora do Instituto Superior de Ciências da Educação de Benguela da universidade Katyavala Buila, constatamos que o ensino da História lecionado no curso de Licenciatura em ensino da História, contribui muito pouco para o desenvolvimento do pensamento crítico e reflexivo, nossa preocupação agudiza-se pelo facto de estarmos perante a formação de professores, aliada a grande necessidade de se formar profissionais críticos e reflexivos para o ensino da História capazes de promover a capacidade critica e reflexiva em seus alunos para que consigam olhar para as questões sociais de forma refletida e questionada em diversos contextos sociais. O estudo consistiu na descrição dos fenómenos em causa, para a recolha da informação recorremos a observação não participante e ao inquérito por questionário. A informação recolhida demonstrou que os inqueridos reconheceram o fraco contributo do ensino da História no desenvolvimento do pensamento crítico e reflexivo dos estudantes que ai se formam e manifestaram a necessidade de adoção de metodológicas e estratégias mais interativas, com vista a promoção de capacidades como: a análise, a crítica, a reflexão e a argumentação e compreensão sobre as questões de envolvência histórica.

PALAVRAS-CHAVE: Pensamento critico e reflexivo, ensino da história, formação de profesores.

\section{INTRODUÇÃO}

O presente estudo, resulta da constatação, enquanto docente no curso de Licenciatura em Ensino de História, do Instituto Superior de Ciências da Educação de Benguela, da Universidade Katiavala
Buíla. Pois que os estudantes que aí se formam têm manifestado dificuldades na construção do pensamento crítico e reflexivo, retirando-lhe a possibilidade de análise, questionamento, compreensão e argumentação em relação à diversidade de temáticas da sociedade actual. Pelas suas características, achamos que a História poderia ser uma disciplina ideal para promover $\mathrm{o}$ desenvolvimento do pensamento crítico e reflexivo dos alunos, ao permitir uma análise do passado, relacionando-o com o presente, no sentido de perspectivar o futuro e ainda pelo facto de que estes estudantes estarem a ser formados para serem profissionais do ensino da História.

Na perspectiva de Barca (1998), o ensino de História não deve ficar restrito a mera repetição de factos e datas, consideradas históricas. Deve permitir ao aluno uma análise crítica das fontes e dados históricos, privilegiando a participação activa dos alunos na construção do conhecimento histórico, numa perspectiva de reflexão e de crítica.

Assim, o presente trabalho apresenta-se como uma investigação descritiva e visa demonstrar que o ensino da história, actualmente tem contribuído muito pouco para o desenvolvimento do pensamento crítico e reflexivo, dos estudantes em referência, o que retira a real possibilidade que a história possui como disciplina curricular. Tal leva-nos a refletir sobre as estratégias metodológicas que podem ser desenvolvidas para que o ensino desta disciplina possa contribuir no desenvolvimento da capacidade de pensar e refletir tornando-os cidadãos autónomos e conscientes dos seus deveres e direitos, dando resposta à questão do exercício da cidadania e enquanto profissionais da educação na área do ensino da história, possam desenvolver um ensino que produza a reflexão crítica dos seus alunos.

\subsection{O que é o pensamento crítico}

As abordagens sobre o pensamento crítico de uma forma geral, parecem vincular-se somente com a filosofia, ciência das indagações. Pois, a reflexão filosófica é um movimento de volta do pensamento sobre si mesmo.

No entanto, pensar criticamente não é só exigido em Filosofia, mas em todas as áreas do cognitivo, assim como em Filosofia, em todas as ciências, cultivar a excelência na reflexão, também o deve ser em História, por ser o estudo do homem no tempo e no espaço.

Para Ennis (1985, p. 46), o pensamento crítico, “é uma forma de pensamento racional, reflexivo, focado no decidir aquilo em que acreditar ou fazer". 
O pensamento crítico pode ser compreendido como sendo um juízo específico baseado na reflexão que se faz mediante a percepção de um determinado fenómeno observado ou experimentado.

Halpern (1989) assume que o pensamento crítico assenta no uso das capacidades cognitivas que aumentam a probabilidade de se obterem resultados desejáveis. Assim sendo "o professor deve agir sempre como ser humano pensante, como intelectual, e não como mero executor de tarefas." (Silva, 1994). Para a autora, é essa reflexão que permite os ajustes necessários para se obter o sucesso. O pensamento critico e reflexivo torna-se ainda muito mais necessário, se compreendermos que o ensino das ciências deve estimular o desenvolvimento de capacidades e habilidades para uma aprendizagem seja de facto significativa.

De acordo com Chaffee (2009), pensamento crítico define-se como o esforço activo, intencional e organizado para compreendermos o nosso mundo, analisando cuidadosamente o nosso pensamento e o dos outros, de modo a clarificar e melhorar essa compreensão, introduzindo a relação com o outro na equação deste conceito.

$\mathrm{O}$ pensamento critico envolve determinada capacidade de argumentação para que o individuo tenha capacidade de refletir, argumentar, criticar e é sempre necessário que se conheça o fenómeno com propriedade, ou que se tenha um conhecimento complexo sobre a questão a ser questionada.

Nesta mesma linha, Guest (2000) define pensamento crítico como um pensamento imaginativo focado no criticismo de argumentos, na avaliação de hipóteses e explanações e na produção de contra argumentos.

Seguno Ennis, Millman (1985), o pensamento crítico pode ser subcategorizado em sete categorias, designadas pelos autores por aspectos do pensamento crítico: a indução, a dedução, o juízo de valor, a observação, a credibilidade, as assumpções e o significado.

Razão pela qual este tipo de pensamento é baseado nas evidências factuais e contextuais, na lógica e envolve um grande esforço intelectual, como clareza, credibilidade especificidade e sobretudo significância.

Para além da noção puramente lógica de argumento válido, as noções de bom argumento, argumento forte e argumento fraco são essenciais á prática da argumentação.

Segundo Lipman (1995):

O pensamento crítico pode produzir uma melhoria na educação, porque aumenta a quantidade e a qualidade do significado que os alunos retiram daquilo que leem $\mathrm{e}$ percebem e que expressam através daquilo que escrevem e dizem". (p. 183)

A crítica é uma atividade do pensamento que envolve julgamentos, análises, avaliações, estabelecimento de relações, mediante alguns padrões.

Lipman (1995) considera que:

o pensamento crítico revela-se sobretudo na capacidade de efetuar "bons julgamentos", ou seja, não basta ser capaz de emitir juízos, é preciso "ampliar as consequências, identificar as características da definição e mostrar a ligação entre estas. (Lipman, 1995, p.171)

O pensamento critico e reflexivo contribui de forma significativa para o desenvolvimento das sociedades na medida em que ao aumentar a capacidade de análise e de argumentação sobre as questões do meio onde o cidadão está inserido e do mundo em geral, que permite também o aprofundamento do conhecimento, a criação de ideias e projectos sociais que se traduzem em uma mais valia para as sociedades. Segundo Lopes (1999), o conhecimento precisa de ser considerado um caminho pelo qual os homens poderão, reflectir, críticar e inserir na prática do seu quotidiano.

$\mathrm{O}$ pensamento crítico e reflexivo melhora e desenvolve a educação e ainda torna os cidadãos mais autónomos, com capacidade de questionamento, reflexão, eloquência e argumentação, tornando-os aptos a entender como identificar e evitar os vários problemas com que se deparam.

Para pensar criticamente é necessário estimular o acto reflexivo, o que significa desenvolver a capacidade de observação, análise, crítica, autonomia, ampliar os horizontes, tornar-se agente activo nas transformações da sociedade, buscar interagir com a realidade (Sordi y Bagnato, 1998).

Razão pela qual, os indivíduos que assim procedem questionam e cruzam todo o tipo de informação que recebem, receando a falsidade dos factos. A dúvida constitui premissa para o desenvolvimento do pensamento critico, pois a principal tendência consiste em precisar as finalidades com rigor e cientificidade. Nesta perspectiva os indivíduos exercem a cidadania com conhecimento profundo amplamente criticado e devidamente refletido dos fenómenos sociais do seu contexto. 


\subsection{O pensamento crítico e o ensino da história}

No contexto actual é fundamental que se reveja novas formas de trabalhar a disciplina de História, rompendo com as formas tradicionais, com conteúdos acabados e com a memorização mecânica das datas e acontecimentos dando a esta disciplina o verdadeiro papel de formadora e promotora do conhecimento social como garantia da cidadania.

De acordo com Schmidt e Cainelli;

o professor de história pode ensinar o aluno a adquirir ferramentas de trabalho necessárias; 0 saber fazer, o saber fazer bem, lançar os germes do histórico. Ele é responsável por ensinar o aluno a captar e a valorizar a diversidade de pontos de vista. Ao professor cabe ensinar o aluno a levantar problemas e a reintegrá-los num conjunto mais vasto de outros problemas, procurando transformar, em cada aula de História, temas em problemáticas. (2004, p. 57).

O ensino da História nas escolas em geral e do ISCED-Benguela em particular é visto como matérias decorativas, em que os alunos em seu papel passivo reproduzem mecanicamente os conteúdos, factos e datas repassados pelos professores com métodos maioritariamente expositivos. O ensino da História proporciona aos alunos não simplesmente a repetição dos feitos históricos mas a reinterpretação e a associação dos diferentes conteúdos, apreendendo e interpretando de acordo com a sua estrutura de conhecimento (Barca, 2003).

O ensino da História deve contribuir para o desenvolvimento de capacidades, levando os indivíduos a analisar, a questionar, a refletir, sobre os acontecimentos, a conhecer as dimensões de tempo e de espaço e a estabelecer as devidas relações entre tais acontecimentos. No entanto, tal não acontece na prática pedagógica diária.

Ainda assim podemos refletir sobre algumas perspectivas em relação ao ensino da História, as quais colocam vários dilemas, como salienta a autora acima citada a saber: Que modelo de História ensinar? Que escalas de História abordar? E que temas e visões selecionar? Não pretendemos entregar receita única e pronta para o ensino da História, nem pretendemos a igualdade no ensino, mas sim um modelo que promova o desenvolvimento de capacidades, habilidades e convicções que estimule os indivíduos ao questionamento e ao pensamento critico e reflexivo, a aceitação da adversidade de opções sobre as temáticas em abordagem.
Pretende-se que estes alunos tenham uma compreensão contextualizada do passado, baseada nas evidências disponíveis e que desenvolvam uma "orientação temporal que se traduza na interiorização de relações entre o passado compreendido, o presente problematizado e o futuro perspectivado" (Barca, 2004, p.134).

Assim deixaríamos de pensar a história como ciência do passado e sim como sendo o estudo contínuo do desenvolvimento social desde a comunidade primitiva até a contemporaneidade, e encontraríamos sim argumentos de razão para evocar nossos pontos de vista com relação ao desenvolvimento da reflexividade e da crítica por intermédio do saber histórico.

Segundo Lopes (1999) o conhecimento precisa de ser considerado um caminho pelo qual os homens poderão, reflectir, criticar e inserir na prática do seu quotidiano.

Para tornar as aulas de História num espaço de produção de conhecimento histórico é necessário que se ensine também os alunos a analisar, refletir e a criticar. Cabrini (2004) refere que:

o ensino da História baseado na análise e reflexão crítica dos factos, produz-se na interacção professor-aluno e acontece através de uma dinâmica capaz de fazer da sala de aula, um espaço de produção de conhecimento, onde a formação do educando perpasse o nível de informação e seja capaz de desenvolver habilidades, defender ideias, enriquecer a sua postura, resgatar valores e atitudes democráticas, criativas, críticas e sadias, tornando-o capaz de realizar a leitura crítica da realidade, bem como, agilizar a sua transformação.

Pensar o ensino de História nesta perspectiva é conceber a sala de aula como um lugar onde o aluno possa participar, criar, pensar, criticar, ter liberdade de formular e reformular suas opiniões e conceitos, construindo respostas e aprofundando seu conhecimento, produzindo saberes com a orientação do professor e não somente pela transmissão, formando assim sua consciência histórica, condição esta que fará dele um individuo activo socialmente. Para tal, Medeiros (2008, p. 20), reforça que:

É nesse sentido que propomos uma viagem reflexiva e analítica no mundo das práticas educativas do ensino de História, por percebermos sua vitalidade no campo da produção do conhecimento, sem perder a sua universalidade, o seu poder formativo, a sua criticidade, além da possibilidade à condução de seres humanos concretos em momentos 
específicos do seu tempo, para compreenderem a sua realidade social e natural.

O professor de História deve dar condição para que o aluno possa participar do processo de fazer, de construção da História e principalmente, transformálo em agente transformador da sociedade.

\section{METODOLOGIA}

Influenciados por Dias (2001) e Marconi e Lakatos (2007) optamos em realizar um estudo descritivo, pois que cingimo-nos em redactar os factos em causa tal como acontecem sem interferir, com objectivo de perceber as causas do fenómeno. Ou seja para percebermos até que ponto o ensino da História contribui para o desenvolvimento do pensamento crítico e reflexivo dos estudantes acima referenciados. Ao constituir o referencial teórico do trabalho, recorremos a pesquisa bibliográfica e encontramos consolo nos dizeres de Marconi e Lakatos (2007), pois que facilitou a escolha dos pressupostos teóricos que foram por nós, analisados e utilizados para compreensão necessária e complexa do fenómeno em estudo e consequentemente deu-nos uma orientação mais precisa para o alcance dos objectivos propostos.

Para tal recorremos a abordagem mista o nos levou a utilizar métodos de índole quantitativa e qualitativa. De acordo com Quivy e Campenhoudt (2008), os métodos de observação directa constituem os únicos métodos de investigação que captam os comportamentos no momento em que eles se produzem e em si mesmos. Para a recolha de dados selecionamos observação não participante utilizando um guião e o inquérito por questionário este como principal instrumento, através deles recolhemos informações sobre as práticas dos professores em sala de aulas, a reação dos alunos as mesmas e as capacidades e habilidades que se desenvolvem nestas aulas.

Relativamente ao tratamento de dados quantitativos recorremos ao sistema informático SPSS (Statistical Package for Social Science) e apresentamos os resultados em tabelas e gráficos. Quanto aos dados qualitativos, procedemos a sua análise através da interpretação directa. As informações disponíveis foram analisadas com recurso ao método de interpretação direta proposto por Stake (2007). A análise do conteúdo dessa informação permitiu-nos estabelecer categorias, a partir das quais ordenámos/agrupámos os dados com vista à avaliação do nosso estudo.

\section{RESULTADOS}

Os resultados obtidos, através da análise dos dados colhidos através dos Questionários, mostram que a maioria dos estudantes considera ter convicções fortes, o que ficou manifestado por $80,9 \%$ dos mesmos.

Quase $60 \%$ dos inquiridos considera que modifica facilmente a sua forma de pensar, enquanto os restantes $38,1 \%$ considera que dificilmente modifica a sua forma de pensar, ao mesmo tempo que consideram ter opiniões bem formadas sobre a maioria dos assuntos que aborda nas aulas de História, o que ficou manifestado por $55,6 \%$ dos inquiridos. Os restantes $41,2 \%$ consideram não ter opiniões formadas em relação à maioria dos assuntos abordados.

A maioria dos inquiridos manifesta ter alguma dificuldade em aceitar facilmente as informações veiculadas nas salas de aulas, pelos professores, o que faz com que privilegiem a análise das fontes de informação, bem como a análise de diferentes pontos de vista, como elementos essenciais na formação de uma opinião, em relação a qualquer assunto.

Os estudantes manifestam também que procuram relacionar os conhecimentos abordados na sala de aulas com a realidade contextual em que vivem, bem como as suas causas, através da análise de diferentes argumentos, o que foi manifestado por mais de $75 \%$ dos inquiridos.

A maioria dos estudantes considera-se bem informada, em relação aos acontecimentos locais e globais, para além de considerar que podem existir mais de uma opinião, em relação ao mesmo assunto, o que foi manifestado por mais de $90 \%$ dos inquiridos, o que faz com que a maioria deles se considere aberta a novas ideias, teorias, concepções e inovações.

Em relação às práticas dos professores no ensino das disciplinas históricas, nota-se ainda uma preferência por metodologias tradicionais, onde a prioridade recai para a transmissão de conhecimentos, por parte do professor, ao mesmo tempo que se enfatiza a memorização dos factos e datas históricos, pelos estudantes, tal como se apresenta no manual.

Embora, alguns professores têm procurado desenvolver um ensino que conduza os estudantes a reflectir sobre os fenómenos estudados, bem como a relacionar os conhecimentos históricos com situações e problemas da actualidade, para além de procurar valorizar as vivências e conhecimentos dos alunos sobre os temas abordados e promover debates 
sobre os temas, relacionando-os com a realidade actual.

No entanto, não tem sido frequente a realização de actividades como visitas de estudo a locais e sítios históricos, bem como seminários especializados para a abordagem de temáticas relacionadas com as disciplinas ou com o curso

De uma forma geral, os estudantes inquiridos consideraram as metodologias utilizadas no ensino das disciplinas históricas como um pouco adequadas, manifestado em $43,7 \%$ das respostas, pouco adequadas, em $23,8 \%$ e nada adequadas, em $4 \%$, ao passo que apenas $23 \%$ dos inquiridos as consideraram adequadas e $5,6 \%$ as consideraram como muito adequadas, tal como se apresenta no gráfico abaixo.

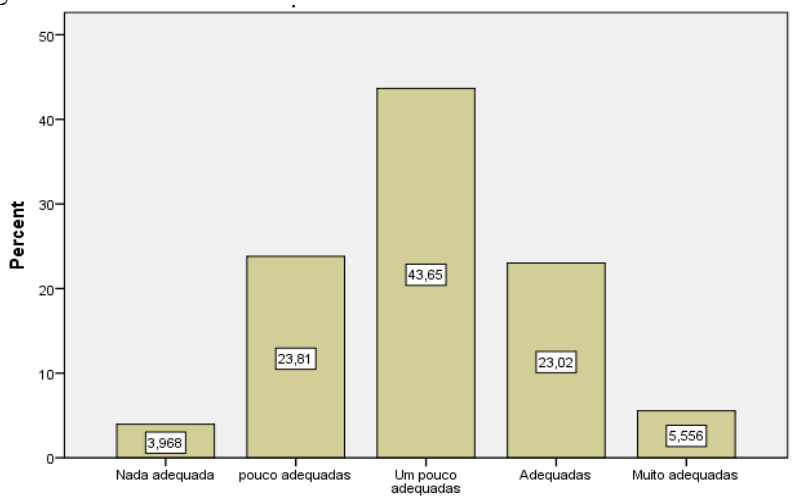

Figura 1. Adequação das metodologias e prácticas dos professores para o desenvolvimento do pensamento crítico e reflexivo dos alunos

Para desenvolvimento do pensamento crítico e reflexivo nas aulas de História, selecionamos um conjunto de actividades que consideramos importantes (1. Descrever diferentes pontos de vista; 2. Explicar um conceito por palavras próprias; 3. Identificar relações entre diferentes acontecimentos e factos históricos; 4. Avaliar a credibilidade de afirmações; 5. Colocar questões para clarificar uma situação; 6. Tirar conclusões a partir dos dados disponíveis sobre determinado fenómeno histórico; 7. Fundamentar as conclusões tiradas; 8. Levantar hipóteses; 9. Apresentar aos outros um raciocínio; 10. Justificar aos outros um raciocínio; 11. Sensibilidade em aceitar as opiniões dos outros; 12. Facilidade na comunicação; 13. Análise de situações; 14. Espírito de observação; 15. Imaginação e criatividade), para verificar qual a frequência da sua ocorrência nas aulas. Neste ponto, verifica-se que as actividades que se realizam com mais frequência, têm a ver com o desenvolvimento da facilidade de comunicação, seguida da análise de situações. A grande maioria das capacidades selecionadas têm sido trabalhadas algumas vezes ou quase sempre.

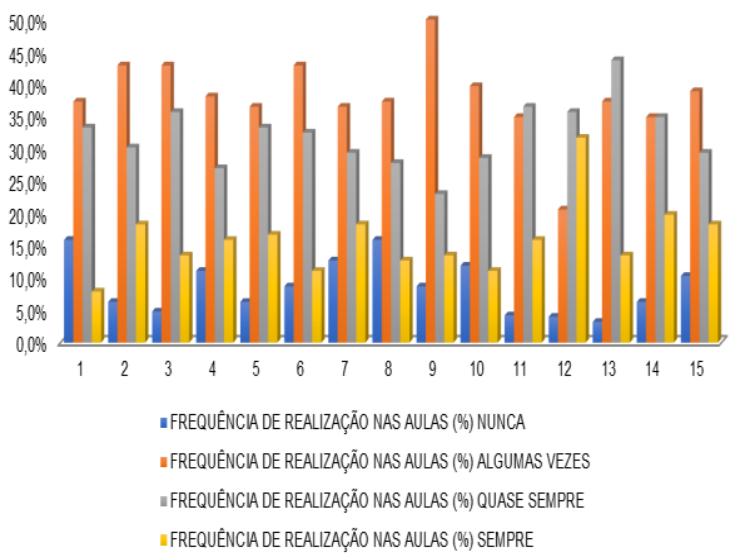

Figura 2. Atividades com maior frequência no ensino da história

No que diz respeito às estratégias de ensino mais eficazes para o desenvolvimento do pensamento crítico e reflexivo, a preferência dos inquiridos, professores e estudantes, recai para as abordagens construtivistas, seguidas, por ordem de preferência, pelos métodos de ensino por problemas, debates/discussões, visitas de estudo e simulações, enquanto que os métodos expositivos são vistos como os menos eficazes.

\section{CONCLUSÕES}

A análise e interpretação dos resultados, tendo em conta os objectivos traçados para a presente investigação, conduziram-nos às seguintes conclusões:

- O ensino da História lecionado nesta Instituição de formação de professores de História contribui muito pouco para a aquisição de capacidades que promovem o desenvolvimento crítico e reflexivo dos estudantes;

- Poucas têm sido as actividades desenvolvidas ao nível das aulas de História no sentido do desenvolvimento do pensamento crítico e acrítico e da formação de valores nos alunos;

- O envolvimento dos alunos em actividades voltadas para a formação do pensamento crítico e reflexivo está resumido à participação nas aulas onde são pouco desenvolvidas as práticas e actividades por nós questionadas no boletim de inquérito;

- Os professores e alunos envolvidos no estudo manifestaram reconhecimento pela importância do desenvolvimento do 
pensamento crítico e reflexivo e demonstraram muito interesse em desenvolver com mais eficácia as actividades promotoras deste tipo de pensamento;

- No âmbito da disciplina de História, privilegia-se, pelos professores envolvidos no estudo, a formação de valores, tais como o nacionalismo, o patriotismo, solidariedade, amor ao próximo, partilha e o pensamento crítico;

- Os professores de alguma forma em suas aulas fazem recurso a práticas desenvolvedoras de capacidades de raciocínio, mas ainda assim muitos professores continuam a centrar-se na aula, protegendo o seu ensino com métodos maioritariamente expositivos, desta feita pouco se contribui para o desenvolvimento do pensamento critico e reflexivo dos formandos.

- Relativamente a abordagem dos conhecimentos históricos, os professores de História em sua prática relacionam muito pouco os conteúdos com a realidade quotidiana dos alunos e por outro lado têm problematizado muito pouco as questões de envoltura social, o que também contribui para o fraco desenvolvimento da capacidade crítica e reflexiva dos estudantes;

- Portanto, torna-se necessário que os professores de História da escola em referência assumam um papel mais activo na formação dos alunos, reavaliando sempre suas práticas e incluindo frequentemente actividades que envolvam capacidades como: a análise, a crítica, a reflexão e a argumentação em sala de aulas. Preocupando-se não apenas com a transmissão de conteúdos históricos, mas também com a sua integração. tendo em vista desenvolvimento da cidadania e do profissionalismo.

\section{REFERENCIAS}

Barca, I. (1998). Verdade e perspectivas do passado na explicação em História: uma visão pósdesconstrucionista. O estudo da História, n. 3. Lisboa: Associação de Professores de História.

Barca, I. (2003). Cognição Situada em História. In. A. Neto et al (org). Didácticas e Metodologias de Educação Percursos e Desafios. Departamento de Pedagogia e Educação. Universidade de Évora.

Cabrini, C. (2004). O Ensino de História-Revisão Urgente. São Paulo: Brasiliense.
Chaffee, J. (2009). Thinking Critically. Boston: Wadsworth.

Dias, (2001). Metodologia das Ciências sociais. São Paulo: Companhia Editora Nacional.

Ennis, R. e Millman, J. (1985). Cornell Critical Thinking Test, Level X. Pacific Grove, CA: Midwest Publications.

Ennis, R. H. (1985). A logical basis for measuring critical thinking skills. Educational Leadership.

Guest, K. (2000). Introducing Critical Thinking to 'Nonstandard' Entry Students. The Use of a Catalyst to Spark Debate. Teaching in Higher Education, 5(3), 289-300.

Halpern, D. (1989). Thought and knowledge: An introduction to critical thinking. $2^{\mathrm{a}}$ ed. Hillsdale, NJ: Lawrence Erlbaum Associates, Inc.

Lipman, M. (1995). O Pensar na Educação. Petrópolis, Rio de Janeiro: Vozes.

Lopes, A. R. C. (1999). Conhecimento escolar: ciência e cotidiano. Rio de Janeiro: UERJ.

Marconi, M. A., e Lakatos, E. M. (2007). Técnicas de pesquisa.

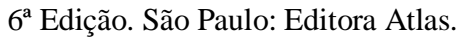

Medeiros, M. F. G. (2008). O ensino da história e o pensamento reflexivo-crítico da professora no $3^{\circ}$ ano do Ensino Fundamental. Dissertação (Mestrado em Educação) Universidade Federal do Rio Grande do Norte. Centro de Ciências Sociais Aplicadas. Programa de PósGraduação em Educação.

Quivy, R., e Campenhoudt, L. (2008). Manual de Investigação em Ciências Sociais. Lisboa: Gradiva.

Schmidt, M. A., e Cainelli, M. (2004). Ensinar História. São Paulo: Editora Scipione.

Sordi, M. R. L. de, e Bagnato, M. H. S. (1998). Subsídios para uma formação profissional crítico-reflexiva na área de saúde: o desafio da virada do século. Rev. latino-am. Enferm. Ribeirão Preto, 6(2), 83-88.

Stake, R. E. (2007). A arte da Investigação com estudos de caso. Lisboa: Fundação Calouste Gulbenkian. 